\section{The Examination of the Effects of Value Modifying Factors on Dairy Farms}

\author{
József Horváth ${ }^{1}$ - Sándor Kovács ${ }^{2}$ \\ ${ }^{1}$ University of Szeged, College of Agriculture, \\ Institute of Economics and Rural Development, \\ Hódmezővásárhely \\ ${ }^{2}$ University of Debrecen, Centre for Agricultural Sciences, \\ Faculty of Agricultural Economics and Rural Development, \\ Department of Economic Analysis and Statistics, Debrecen \\ horvath@mfk.u-szeged.hu
}

\section{SUMMARY}

We wish to present a method to quantify the value modifying effects when comparing animal farms. To achieve our objective, multi-variable statistical methods were needed. We used a principal component analysis to originate three separate principal components from nine variables that determine the value of farms. A cluster analysis was carried out in order to classify farms as poor, average and excellent. The question may arise as to which principal components and which variables determine this classification.

After pointing out the significance of variables and principal components in determining the quality of farms, we analysed the relationships between principal components and market prices. Some farms did not show the expected results by the discriminant analysis, so we supposed that the third principal component plays a great role in calculating prices. To prove this supposition, we applied the logistic regression method. This method shows how great a role the principal components play in classifying farms on the basis of price categories.

Keywords: animal farm valuation, value modifying effects, multivariable statistical methods, market price

When studying animal farms to express the value modifying effects of, e.g. fodder area, it must be remembered that there are several other factors in addition to the fodder production area which determine the value of a farm (Boyce, 1982). According to European Valuation Standards (2003) the market value represents the price for which the property might be sold within a civil law contraction realized between a seller showing willingness to buy and a purchaser being not connected with the seller at the time of the evaluation, supposing the facts that the property gains market publicity, the market conditions make the usual sale possible, furthermore, there are enough time for the marketing negotiation, relating to the nature of the property. In the present study, we present a method to quantify the value modifying effects when comparing animal farms.

To reach our objectives, multivariable statistical methods were needed. We had difficulties with the amount of data, since a multiple of the number of the variables is needed to obtain correct and reliable results. However, the market produces the comparing data, so gathering more information would make the observations effective.

We managed to gather information on sale or purchasing offers for 19 relevant dairy farms. As to assess the reliability of our rating data we use Reliability Analysis. The principle aim of reliability analysis is to determine the degree of agreement between rates when using a particular rating scheme. If the reliability is low, then the scheme itself may be at fault, or the rates, or both (Barrett, 2001). The so called Chronbach's Alpha coefficient determines the reliability, its value should be at last 0,7 . Realistically, values above about 0.7-0.8 are acceptable for applied tests (Barrett, 2001). We compute coefficient alpha as 0,82 , so the survey responses are valid.

Before studying the connections between them, we grouped the variables thematically and thus incorporated similar variables so that we could handle them easier. Table 1 shows the nine variables contracted from the original 17 factors.

All nine variables are interconnected, their individual roles can hardly be measured, thus to estimate their value modifying effects, further data reduction is needed. Loss of information may occur during this process, but the requirement should be fulfilled that the information content of the dataset should be kept on a high level. With the help of principal component analysis, three separate principal components were originated from nine variables (Table 2), which kept $84,5 \%$ of the original informational content (Table 3). Principal component analysis is a statistical method which transforms a variable stock into a new variable stock containing fewer variables with the help of linear transformation (Székelyi and Barna, 2002).

Every variable belongs to one principal component, except for the variable „farm facilities”. This variable is classified both in the second and third principal component due to the similar principal component weights. We should mention here that the breeding animal variable was taken out, as it appeared with the same weight in every principal component. In this way, the examination should be done on only eight variables.

It is also important to verify that the discovered principal components are valid, so we did a reliability analysis. Chronbach's alpha coefficients were 0,91 and 0,85 for the PC 1 and PC 2. Because they are greater than 0,7 , the scales of the principal components are reliable. The PC 3 only consists of the seed-crop variable, so it is appropriate. 
Thematic classification of the value modifying factors

\begin{tabular}{|c|c|}
\hline Original Factors & Contracted Factors \\
\hline Farm facilities (shape, location, slope, soil) & \multirow{3}{*}{ Location, Infrastructure } \\
\hline Approaching & \\
\hline Infrastructure (electricity, water, gas, drainage, telephone, fax, Internet) & \\
\hline Booking net value of buildings and technological equipment & Booking Value \\
\hline Technical state of major building structure elements (base, wall, roof) & \multirow{5}{*}{ Technical Status } \\
\hline Technical state of windows, doors, covers, and technological equipment & \\
\hline Design failures, faults and damage & \\
\hline Date of building and renovation & \\
\hline Utilising aspects, state of maintenance & \\
\hline Modernity of technology, the technological organization & Modernity of Technology \\
\hline Fodder production area & Fodder Production Area \\
\hline Local labour market, demography, neighbourhood of cities & Labour Market, Demography \\
\hline Value of breeding stock & Value of Breeding Stock \\
\hline Animal welfare and environmental aspects relevant to EU regulations & \multirow{2}{*}{ Animal Welfare and Environmental Aspects } \\
\hline Neighbourhood of buildings, polluting sources & \\
\hline Opportunity to change function, to rebuild, to share and to expand & \multirow{2}{*}{ Legal Opportunities and Limits } \\
\hline Rights and facts in real estate registration (e.g. mortgage) & \\
\hline
\end{tabular}

Source: own research

The principal components of variables by Weight

\begin{tabular}{|l|c|c|c|}
\hline \multirow{2}{*}{\multicolumn{1}{|c|}{ Variables }} & \multicolumn{3}{c|}{ Principal Components } \\
\cline { 2 - 4 } & $\mathbf{1}$ & $\mathbf{2}$ & $\mathbf{3}$ \\
\hline Booking Value & $\mathbf{0 , 9 3 6}$ & & \\
\hline Modernity of Technology & $\mathbf{0 , 9 3 2}$ & & \\
\hline Technical Status & $\mathbf{0 , 9 0 4}$ & & \\
\hline Legal Limits & & $\mathbf{0 , 9 2 5}$ & \\
\hline $\begin{array}{l}\text { Animal Welfare and } \\
\text { Environmental Protection }\end{array}$ & & $\mathbf{0 , 8 0 4}$ & \\
\hline Labour & & $\mathbf{0 , 7 8 1}$ & \\
\hline Farm Facilities & & $\mathbf{0 , 7 2 2}$ & $\mathbf{0 , 4 1 4}$ \\
\hline Fodder Production Area & & & $\mathbf{0 , 9 3 6}$ \\
\hline Source: own
\end{tabular}

Source: own research

Table 3

The effect of main components on preserving information

\begin{tabular}{|c|r|r|}
\hline Components & $\begin{array}{c}\text { Content of } \\
\text { Information (\%) }\end{array}$ & $\begin{array}{c}\text { Cumulated Content } \\
\text { of Information (\%) }\end{array}$ \\
\hline $\mathbf{1}$ & $\mathbf{3 9 , 4}$ & $\mathbf{3 9 , 4}$ \\
\hline $\mathbf{2}$ & $\mathbf{3 3 , 3}$ & $\mathbf{7 2 , 8}$ \\
\hline $\mathbf{3}$ & $\mathbf{1 2 , 6}$ & $\mathbf{8 5 , 4}$ \\
\hline 4 & 6,9 & 92,3 \\
\hline 5 & 4,9 & 97,1 \\
\hline 6 & 1,2 & 98,3 \\
\hline 7 & 0,9 & 99,3 \\
\hline 8 & 0,7 & 100,0 \\
\hline
\end{tabular}

Source: own research

The classification of the farms was carried out on a scale ranging from 1 to 5 , where a score of 1 is unfavourable, while a score of 5 is an excellent qualification. We created three mechanical qualification classes based on the average scores of the farms. The lower third were called the group of „poor farms", the middle part is the group of ,average farms", and the upper part is the group of ,excellent farms”.
We carried out a cluster analysis on these results. We wanted to know whether the mechanical classification of the farms fits to that realised in the cluster analysis. The aim of the procedure was to classify the farms into homogenous groups according to the chosen variables, in a way that the farms belonging to the same group should be similar, but should differ from the members of other groups. We applied the so-called centroid method of cluster analysis, which resulted in three groups being not far from the mechanical classification, because $73,7 \%$ of the mechanical grouping were correctly classified (Table 4).

Table 4

Classification of farms by mechanical and centroid method

\begin{tabular}{|c|c|c|c|c|c|}
\hline \multirow{2}{*}{\multicolumn{2}{|c|}{ Denomination }} & \multicolumn{3}{|c|}{ Mechanical Classification } & \multirow{3}{*}{\begin{tabular}{|c}
$\begin{array}{c}\text { Total } \\
\text { (Centroid } \\
\text { Method) }\end{array}$ \\
5 \\
\end{tabular}} \\
\hline & & \multirow{2}{*}{$\begin{array}{r}\text { Poor } \\
5\end{array}$} & \multirow{2}{*}{$\begin{array}{r}\text { Average } \\
0 \\
\end{array}$} & \multirow{2}{*}{\begin{tabular}{|r|} 
Excellent \\
0 \\
\end{tabular}} & \\
\hline \multirow{3}{*}{$\begin{array}{l}\text { Centroid } \\
\text { Method }\end{array}$} & Average & & & & \\
\hline & Excellent & 1 & 5 & 3 & 9 \\
\hline & Poor & 0 & 1 & 4 & 5 \\
\hline \multicolumn{2}{|c|}{$\begin{array}{l}\text { Total (Mechanical } \\
\text { Classification) }\end{array}$} & 6 & 6 & 7 & 19 \\
\hline
\end{tabular}

Source: own resource

We carried out a cluster analysis even on the variables. Our aims were to show what kind of variable groups may be created, and to find those variables in which the difference between the connected farms is minimal. We had already decreased the number of variables; thus the question is how the mechanical qualification differs from the one made by cluster analysis on principal components. To demonstrate this we did a cluster analysis even on the principal components too (Table 5). 
Table 5

Cluster according to the original variables and the principal components

\begin{tabular}{|c|c|c|}
\hline $\begin{array}{c}\text { Qualification } \\
\text { Classes }\end{array}$ & $\begin{array}{c}\text { Elements of Cluster } \\
\text { on the Base of the } \\
\text { Original Variables }\end{array}$ & $\begin{array}{c}\text { Elements of Cluster } \\
\text { on the Base of the } \\
\text { Principal Components }\end{array}$ \\
\hline Poor & J, K, L, M, S & J, K, L, M \\
\hline Average & $\begin{array}{c}\text { A, B, D, E, G, H, I, } \\
\text { N, T }\end{array}$ & D, E, G, H, N, T, S \\
\hline Excellent & C, F, O, P, R & A, B, C, F, I, O, P, R \\
\hline
\end{tabular}

Source: own research

Of the 19 total, the farms marked with A, B, I and $\mathrm{S}$ were classified into other qualification classes during the classification on principal components.

Farms A, B, and I moved from the average class to the excellent class, while farm $\mathrm{S}$ went from the poor class into the average class. There must not be the data reduction behind the difference in classifications, because the PC's explain the $85 \%$ of the total variance. A question may be asked as to which principal components and which variables cause the different classification. Figure 1 shows that the value of the third principal component of farms $\mathrm{A}, \mathrm{B}$ and $\mathrm{I}$ is higher than that of the other components. The first principal component has a more favourable classification of farm $\mathrm{S}$ compared with farms $\mathrm{J}, \mathrm{K}, \mathrm{L}$ and $\mathrm{M}$.
Figure 1: The observed principal component values of the dairy farms

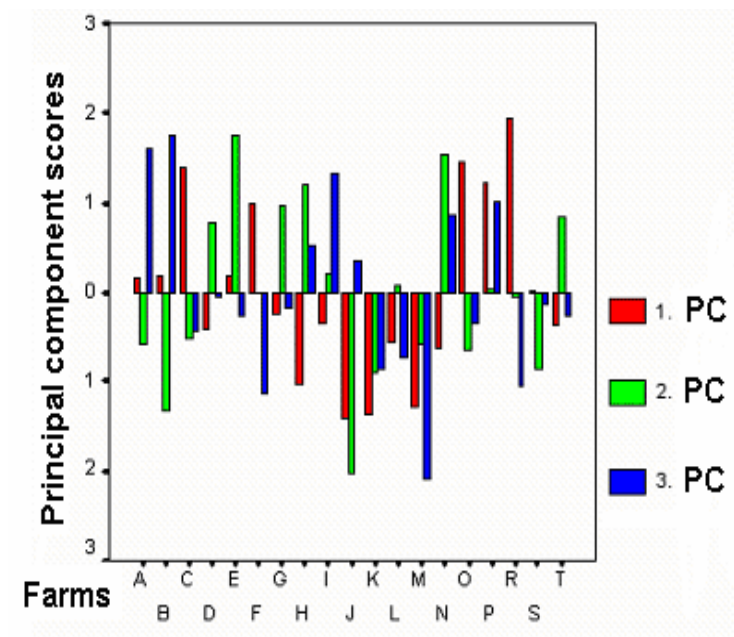

Resource: private counting

The first principal component plays the greatest role - greater than the third principal component plays - in the classification of the farms into various categories. The second principal component was of great importance, mainly in classifying farms with poorer quality. Table 6 and Figure 1 prove these statements.

Mean and standard deviation of variables by quality categories

\begin{tabular}{|c|c|c|c|c|c|c|c|c|}
\hline \multirow{3}{*}{ Variables } & \multicolumn{6}{|c|}{ Quality categories } & \multirow{2}{*}{\multicolumn{2}{|c|}{ In the total sample }} \\
\hline & \multicolumn{2}{|c|}{ Poor } & \multicolumn{2}{|c|}{ Average } & \multicolumn{2}{|c|}{ Excellent } & & \\
\hline & Mean & St. Dev. & Mean & St. Dev. & Mean & St. Dev. & Mean & St. Dev. \\
\hline Location, Infrastructure & 2,69 & 0,63 & 4,48 & 0,44 & 3,47 & 0,60 & 3,74 & 0,93 \\
\hline Net booking value & 1,40 & 0,55 & 2,22 & 0,67 & 4,40 & 0,89 & 2,58 & 1,35 \\
\hline Technical status & 2,24 & 0,89 & 2,73 & 0,58 & 4,40 & 0,35 & 3,04 & 1,05 \\
\hline Modernity of technology & 1,60 & 0,89 & 2,67 & 0,71 & 4,40 & 0,89 & 2,84 & 1,30 \\
\hline Fodder production area & 3,20 & 0,84 & 4,56 & 0,53 & 3,40 & 0,89 & 3,89 & 0,94 \\
\hline Labour market, Demography & 2,40 & 0,89 & 3,78 & 0,97 & 3,00 & 0,71 & 3,21 & 1,03 \\
\hline Animal Welfare and Environmental Aspects & 2,90 & 0,55 & 4,22 & 0,75 & 4,20 & 0,76 & 3,87 & 0,90 \\
\hline Legal opportunities and Limits & 3,00 & 0,61 & 3,94 & 0,95 & 2,90 & 0,42 & 3,42 & 0,89 \\
\hline Per cow price & 99 & 30 & 229 & 142 & 221 & 54 & 193 & 115 \\
\hline
\end{tabular}

Source: own calculation

To confirm the results of the cluster analysis using the centroid method, we used DA (discriminant analysis) to analysing the importance of the principal components in qualifying the farms. DA using 2 discriminating functions classified three quality classes. This result is exactly the same as the one we obtained using cluster analysis (Table 7).

The first discriminant function consists of the first principal component with a high discriminant weight (close to 1.0). However, the second discriminant function consists of the second and third PC, with approximately the same weights (close to 0.5) (Table 8).
Table 7

Comparison of the results of discriminant analysis and cluster analysis

\begin{tabular}{|c|c|r|r|r|r|}
\hline \multirow{4}{*}{$\begin{array}{c}\text { Classification } \\
\text { by Cluster } \\
\text { Analysis }\end{array}$} & Quality & \multicolumn{3}{|c|}{ Classification by DA } & \multirow{2}{*}{ Total } \\
\cline { 2 - 6 } & classes & Poor & Average & Excellent & \\
\cline { 2 - 6 } & Poor & $\mathbf{5}$ & & & 5 \\
\cline { 2 - 6 } & Everage & & $\mathbf{9}$ & & 9 \\
\hline Total & & 5 & 9 & 5 & 5 \\
\hline
\end{tabular}

Source: own calculation 
by qualities, so further conclusions could be reached Structure matrix of discriminant functions (Table 10).

\begin{tabular}{|c|r|r|}
\hline \multirow{2}{*}{ Principal Components } & \multicolumn{2}{|c|}{ Discriminant Weights } \\
\cline { 2 - 3 } & $\begin{array}{c}\text { 1. Discriminant } \\
\text { Function }\end{array}$ & $\begin{array}{c}\text { 2. Discriminant } \\
\text { Function }\end{array}$ \\
\hline 1. PC & $\mathbf{0 , 9 8}$ & 0,01 \\
\hline 2. PC & 0,03 & $\mathbf{0 , 4 8}$ \\
\hline 3. PC & $-0,04$ & $\mathbf{0 , 4 3}$ \\
\hline
\end{tabular}

Source: own calculation

Table 9 represents the average scores of both discriminant functions in the various classes. As a matter of fact, the average scores of the first discriminant function could be calculated by the first Principal Component's average scores. The second discriminant function's average scores were calculated by the weights of the second and third Principal Component's average scores. The weights are shown above in Table 8.

Table 9 Average discriminant scores of quality groups by discriminant functions

\begin{tabular}{|c|r|r|}
\hline \multirow{2}{*}{ Quality classes } & \multicolumn{2}{|c|}{ Discriminant Scores } \\
\cline { 2 - 3 } & \multicolumn{1}{|c|}{ Function 1 } & \multicolumn{1}{c|}{ Function 2 } \\
\hline Poor & $-2,02$ & $-2,06$ \\
\hline Average & $-0,60$ & $\mathbf{1 , 5 8}$ \\
\hline Excellent & $\mathbf{3 , 1 0}$ & $\mathbf{- 0 , 7 9}$ \\
\hline
\end{tabular}

Source: own calculation

The completed DA suitably proves our previous assumptions. We could observe that the high score of the first discriminant function among ,excellent" dairy farms indicates that the first PC, including the technical conditions, has great importance in determining the qualities of farms. We could also note that the second discriminant function's average scores in the case of the average farms are much higher than in case of the ,excellent” ones. This proves that the significance of the second and third principal components is determinant in the case of ,average farms".

After we pointed out the significance of variables and PCs (Principal Components) in determining the quality of farms, we analysed the relationships between PCs and market prices. To do this, we involved the ,per cow prices" component among the variables applied in PC and then used cluster analysis. As a result, 2 clusters were separated which could be labelled as low and high price category clusters. Originally, three groups were made by the SPSS program but there were only one farm $(\mathrm{H})$ classified into the third group because of its prominently high per cow price. This was caused by the very high scores of the second PC. In order to simplify the procedure, we put that farm into the second class (high price category).

As a result of the cluster analysis ,poor and average farms" were classified into the low price category, and the ,excellent" farms were classified into the high price category. The categories classified by price do not clearly cover the categories classified

Price category classification of quality categories

\begin{tabular}{|c|c|c|c|}
\hline \multirow{2}{*}{\multicolumn{2}{|c|}{ Labels }} & \multicolumn{2}{|c|}{$\begin{array}{l}\text { Number of farms in price } \\
\text { categories by Centroid Method }\end{array}$} \\
\hline & & Low price & High price \\
\hline \multirow{3}{*}{$\begin{array}{l}\text { Quality } \\
\text { classes }\end{array}$} & Poor & 5 & 0 \\
\hline & Average & 6 & 3 \\
\hline & Excellent & 1 & 4 \\
\hline
\end{tabular}

Source: own calculation

Farms: „B”, „H” and „N” were put into the high price category in spite of the fact that they are average farms. This can be explained by the fact that the second and third PC scores are very high in the case of these farms. Farm „F” was placed into the „excellent” group, but was ranked into the low price category. It is true that the first PC score of this farm (F) is high enough, but the third PC score is extremely low, that caused the decrease in the value. From the data of the farms with unexpected results we supposed that the third PC plays a great role in calculating the prices.

To prove the previous assumption we applied Logistic Regression Method. This method will show what a great role the given PCs have in classifying farms into price categories (Wuensch, 2004). Table 11 contains the results of the model.

Table 11

Principal component influences on prices

\begin{tabular}{|l|r|r|}
\hline Label & \multicolumn{1}{|c|}{ Odds Ratio } & \multicolumn{1}{|c|}{ Weight } \\
\hline 1. PC & $\mathbf{5 , 0 8 4}$ & $\mathbf{0 , 5 1 8}$ \\
\hline 3. PC & 2,830 & 0,330 \\
\hline
\end{tabular}

Source: own calculation

The weights were calculated in the same way as the OLS regression B coefficients and could be interpreted the same way (their values change between 0 and 1). During the previous test the SPSS 10. program calculated the model shown above. We could observe that odds ratio of the first PC is 5.08 and in case of second $\mathrm{PC}$ it is 2.83. This means the first $\mathrm{PC}$ plays an eighty- percent greater role in price calculation than the third PC.

We sorted the samples into three equal groups, by price. We particularly analysed the upper third part, including farms with the highest price, and concluded that the odds ratios of the first and third PC are almost exactly the same, so their influences on prices were very close and balanced (Table 12). Consequently, their role could be treated in the same way in calculating the highest prices.

Table 12

PC influences in case of farms with the highest price

\begin{tabular}{|c|r|r|}
\hline Label & \multicolumn{1}{|c|}{ Odds Ratio } & \multicolumn{2}{|c|}{ Weight } \\
\hline 1. PC & 3,322 & 0,381 \\
\hline 3. PC & 3,022 & 0,351 \\
\hline
\end{tabular}

Source: own calculation 
As we investigated the lower third part of the sample the third PC was left out from the model and instead of it the second PC appeared in the model with almost the same weight as the first PC involved into the model. It can be observed that in the lower third part by price the second $\mathrm{PC}$ is less significant than the first PC, but the first PC is more efficient in growing the odds to get into better price categories. The second PC - which includes protection of animals and environment - mainly has a great role in increasing the odds by taking the farms with the lowest price (Table 13).

Table 13

PC influences on prices in case of the farms with the lowest price

\begin{tabular}{|c|r|r|}
\hline Label & \multicolumn{1}{|c|}{ Odds Ratio } & \multicolumn{2}{|c|}{ Weight } \\
\hline 1. PC & $\mathbf{4 , 8 0 3}$ & 0,440 \\
\hline 2. PC & 3,907 & $\mathbf{0 , 5 0 6}$ \\
\hline
\end{tabular}

Source: own calculation
Finally from the summarised model results we could make a statement that it is the first PC, that is the most efficient in calculating the prices as well as classifying into quality classes, but the third PC also has a great importance. We also analysed the Principal Components element by element.

In Table 14 it is obvious that in case of the first PC in view of both odds ratios and weights the technological modernity factor of the farm is the dominant factor. It is also remarkable that in the case of the second PC, in view of both odds ratios and weights, the protection of animals and environment factor of the farm is the dominant factor. The very small values of the weight were caused by the poor significance of the second PC in calculating the prices. It can be observed that in case of the third PC in view of both odds ratios and weights the fodder production area factor is the dominant one. Nevertheless according to Hand and Lev (2003) investigations wealth and growth in modern economies are driven primarily by intangible assets.

Table 14

The influences of the PC elements on calculating prices

\begin{tabular}{|c|c|c|}
\hline Label & Odds Ratio & Weight \\
\hline Technological conditions $\left(\mathrm{l}^{\text {st }} \mathrm{PC}\right)$ & 0,33 & $-0,19$ \\
\hline Net Booking Value $\left(1^{\text {st }} \mathrm{PC}\right)$ & 1,21 & 0,05 \\
\hline Modernity of technology $\left(1^{\text {st }} \mathrm{PC}\right)$ & 6,64 & 0,40 \\
\hline Labour market, Demography $\left(2^{\text {nd }} P C\right)$ & 0,26 & $-0,03$ \\
\hline Legal opportunities and limits $\left(2^{\text {nd }} P C\right)$ & 0,02 & $-0,07$ \\
\hline Animal welfare and environment protection $\left(2^{\text {nd }} \mathrm{PC}\right)$ & 163,27 & 0,09 \\
\hline Location, Infrastructure $\left(2^{\text {nd }} P C\right)$ & 5,72 & 0,03 \\
\hline Location, Infrastructure $\left(3^{\text {rd }} \mathrm{PC}\right)$ & 1,14 & 0,10 \\
\hline Fodder production area $\left(3^{\text {rd }} \mathrm{PC}\right)$ & 1,54 & 0,32 \\
\hline
\end{tabular}

Source: own calculation

\section{REFERENCES}

Barrett, P. (2001): Assessing the Reliability of Rating Data. http://www.pbarrett.net/rater.pdf

Boyce, B. N. (1982): Real Estate Appraisal Terminology. Ballinger Publishing Company, Cambridge, 234.

Hand, J.-Lev, B. (2003): Intangible Assets. Values, Measures and Risks. Oxford University Press, Oxford, 525.

Székelyi, M.-Barna, I. (2002): Túlélőkészlet az SPSS-hez.
Többváltozós elemzési technikákról társadalomkutatók számára. Typotex Kiadó, Budapest, 453.

Wuensch, K. L. (2004): Binary Logistic Regression with SPSS (manuscript) 13.

European Valuation Standards (2003): The European Group of Valuers' Associations, London, 428. 